ingredients in the vehicle themselves not regarded as spermicides. P. E. Lindahl (Sweden) described how he has replaced the upper and lower glass surfaces of the cell used in the Davidson test by semipermeable membranes, permitting the access of oxygen, since he believes conditions within the vagina to be aerobic, not anaerobic. J. Macleod (New York) said that a special laboratory has been set up at the Sanger Bureau of the International Planned Parenthood Federation, with the express purpose of investigating all the existing methods of spermicidal testing. He himself believed that fundamental studies on spermigration are urgently needed.

There were two papers on the effects on pregnancy of certain antimetabolites and nucleotoxic compounds. J. M. Robson and D. Jackson (London) considered three groups of substances-spindle poisons, such as podophyllotoxin, colchicine and demecolcine; mitotic poisons, such as chlorambucil and nitrogen mustards; and antimetabolites, such as 6-mercaptopurine and furazolidone. Most of these were effective in interrupting pregnancy, some even before the stage of implantation; but, in general, the therapeutic ratio was too low for them to have any practical value. Of those agents which were effective before implantation, the antimetabolites seemed most promising. J. Yudkin, B. P. Wiesner and Miriam Wolfe had found $\beta$-peltatin less active, but with a higher therapeutic ratio than podophyllotoxin. $\alpha$-Peltatin was more active and less toxic than $\beta$-peltatin. Two doses, given on successive days, were more effective than a single dose. Demecolcine was very effective, but the escaped litters after marginal doses showed many congenital abnormalities and the surviving offspring had impaired fertility. It was promising for future research that slight changes in chemical structure markedly influenced both effectiveness and toxicity.

M. G. Scott and Patricia P. Scott (London) have made detailed studies of the effects on the reproductive organs of cats of chronic infections, dietary inadequacies and ligation of the pancreatic duct. These all led to retardation of development and regression of the gonads and accessories. In the testes abnormal cell types were seen, while poor follicular activity was found in the ovaries. It was concluded that the primary effect in all cases was malnutrition rather than a direct influence of the chronic infection, and that it was exerted on the anterior pituitary body, the gonadal changes being secondary.

Hilda M. Bruce (London) said that all the hamsters at present in the western hemisphere were descendants of a single litter found at Aleppo twenty-five years ago. About twelve varieties were now recognized. Of these, the ruby-eyed fawn mutant showed genetic sterility in the male. Her investigations on this revealed that fertility is confined to a period of 2-3 weeks after puberty, the subsequent progressive infertility being due to increasing defect of spermato. genesis. The testicular histology showed disorganization of isolated tubules even in young and still fertile animals; this process progressed with advancing age so that by 150 days sterility was complete. Multinucleate cells (similar to those found by Scott and Scott in their subnormal cats) appeared. In the ensuing discussion, T. Mann pointed out that copper-containing enzymes are implicated in both pigment formation and spermatogenesis, suggesting a possible enzyme defect as the basis for the genetic sterility.
Delphine M. V. Parrott (London) described a technique for orthotopic ovarian grafting which avoided the difficulties of surgical removal of the ovaries in the recipient mouse, by subjecting the animals to $900 \mathrm{r}$. of whole-body irradiation, followed by the injection of bone marrow from other mice. A later modification was to give two successive doses of $450 \mathrm{r}$. since, although the effect on the ovary is cumulative, the systemic effects of a given dose (if not lethal) are relatively short-lived. Orthotopic grafts made four weeks after irradiation proved fertile, but if grafting were delayed until nine weeks after irradiation, fertility was reduced, perhaps because of the reduced blood supply to the very atrophic ovarian remnant.

J. L. Hancock (Cambridge) has made an exam. ination of cleaved ova recovered after natural or artificial insemination of sows in order to assess the fertilization-rates. He found 90.5 per cent cleavage after natural matings, but only $21 \cdot 7-47 \cdot 8$ per cent after artificial insemination. The highest rates with the latter were obtained when undiluted semen or semen diluted with egg-yolk glucose phosphate diluent was used $(46 \cdot 2$ and $47 \cdot 8$ per cent cleavage). When semen diluted as above but stored for twentyfour hours at $5^{\circ} \mathrm{C}$. was used, the rate was only 21.7 per cent, and when semen diluted with seminal plasma was inseminated the rate was $22 \cdot 2$ per cent. It was also observed that the number of spermatozoa in the zona pellucida of recovered eggs was in general considerably lower after artificial insemination than after natural mating. There seems little doubt that the efficiency of artificial insemination compares unfavourably with that of natural mating.

G. I. M. SWYER

\section{AGRICULTURE AT CAMBRIDGE}

A COLLECTION of eleven review articles which $A$ have prefaced the Memoirs of the School of Agriculture, Cambridge, over the past few years has recently been published as the first volume of "Agricultural Research and Teaching at Cambridge"*. As Sir Frank Engledow points out in a foreword it is always profitable to ponder objectives and achievements of the past in deciding courses for the future, and these articles review in some detail the researches and achievements by members of the staff of the School of Agriculture in particular fields. A historical review of researches in the physiology of reproduction is made by $\mathrm{F}$. H. A. Marshall in which he traces the development of this subject from the founding of a university lectureship in agricultural physiology in 1908. Kenneth Smith summarizes twenty years of virus research, and G. D. H. Bell describes how the application of genetical principles to the breeding of agricultural plants was the inspiration for the establishment of the Plant Breeding Institute in 1912. The researches in animal nutrition are reviewed by E. T. Halnan. The Horticultural Research Station was opened in 1922, and R. M. Woodman describes the changes in the character of the work which have taken place since then. 'The study of agricultural economics commenced as early as 1896 with the endowment of a lectureship in this subject by Sir Walter Gilbey,

* University of Cambridge: School of Agriculture. Agricultural Research and Teaching at Cambridge, Vol. 1 (comprising Review Series, Nos. 1-11). Pp. 72. (Cambridge : University School of Agriculture, 1957.) 7s. $6 d$. 
and the late A. W. Menzies-Kitchen traces its development up to 1951 . H. H. Nicholson describes the evolution of field drainage investigations which commenced in 1930 at the suggestion of Sir Frank Engledow. J. Hammond gives an account of animal production research, including the breeding experirnents of Punnett which led to the establishment of the Poultry Research Station. The history of Cambridge University Farm, from the leasing of Burgoynes Farm between 1900 and 1910 and its establishment on the present site, is related by W. S. Mansfield, the director. F. Hanley details the development of erop husbandry experiments from 1894 onwards. The final review is by Sir Frank Engledow, who describes the changes in agricultural teaching at Cambridge between 1894 and 1955 .

These collected reviews give a very complete picture of the progress in agricultural research at Cambridge from the end of the past century, when it was considered doubtful whether it was proper for the University to raise agriculture to the status of a Department with a chair, to the present time, when the importance of agriculture in the national economy alone is ample justification for sound teaching and research.

E. C. Humphries

\section{NIGHT-VISION EFFICIENCY}

$\mathrm{D}$ URING the Second World War the practical need arose of selecting military personnel for tasks requiring high visual performance at night, and various tests of 'night-vision efficiency' were therefore devised. The Medical Research Council initiated a study of these tests, and has recently published a report* of its findings. The report consists largely of experimental work and makes the following positive contribution to this difficult topic : absolute thresholds vary from individual to individual, and the amount of light an individual requires to perform an acuity discrimination (detecting the orientation of a Landolt $C$ ) and a more complex perceptual task (identifying objects in a dimly lit Hogarth print) is strongly correlated with his absolute threshold, provided that these tests are such that rods, not cones, are operative.

Minor technical eriticisms can be made; for example, the frequency of positive responses to 'blank' stimuli is not reported, though this is an important index of the subject's reliability, and the figure must have been used in making the 'guessing correction' when the thresholds were determined by the procedure described in an appendix (a war-time report by H. K. Hartline and P. R. MeDonald for the United States Committee on Aviation Medicine). The absolute threshold seems to be more variable than many other visual functions, such as optimum acuity, critical fusion frequency and differential threshold; it would be interesting to know why this is so, but the authors offer no experiments which throw more light on the matter. Nor have they made a serious attempt to assess the relative importance of this particular factor compared with the many other factors (for example, variations in pupil size, residual refractive error, night myopia, avoidance of foveal fixation, pattern of eye movements, reliability of * Medical Research Council. Special Report Series No. 294 : Individual Differences in Night-Vision Efficiency. By M. H. Pirenne, F. H. C. Marriott and E. F. O'Doherty. With a section on The Frequency of Seeing at Low lllumination by $H$. K. Hartline and P. R. 1957.) 8s. net. response, intelligence, motivation, etc.), which may also be important in causing variations in visual performance at low illuminations. Nevertheless, a positive, well-established result is valuable in a field full of conflicting claims, and the experiments on acuity at low illuminations will interest visual physiologists.

H. B. Barlow

\section{STATISTICAL ANALYSIS OF A RANDOM, MOVING SURFACE}

A THEORETICAL study, by Dr. M. S. LonguetA Higgins, of the statistical properties of a surface the elevation of which is given by the superposition of a large number of simple harmonic waves with random phases travelling in different directions has recently been published under the title "The Statistical Analysis of a Random, Moving Surface"*. At time $t$, the elevation (measured from the mean level) at a point in the surface the co-ordinates of which are $(x, y)$ is taken to be

$$
\zeta(x, y, t)=\sum_{n} c_{n} \cos \left(u_{n} x+v_{n} y+\sigma_{n} t+\varepsilon_{n}\right)
$$

where the phases $\varepsilon_{n}$ are distributed independently and uniformly over the interval $(0,2 \pi)$, and the angular frequency

$$
\sigma_{n}=\sigma\left(u_{n}, v_{n}\right)=\sigma\left(\sqrt{u_{n}+v_{n}}\right)
$$

the function $\sigma$ depending on the type of wave motion and the medium in which it takes place. In the limit as $n \rightarrow \infty, \zeta$ becomes a two-dimensional stationary normal stochastic process, the properties of which are completely determined by the spectral density of energy $E(u, v)$, defined by:

$$
\underset{\substack{u_{n} \leqslant u \\ v_{n} \leqslant v}}{\sum \int_{\frac{1}{2}}^{2}}=\int_{-\infty}^{u} \mathrm{~d} u^{\prime} \int_{-\infty}^{v} \mathrm{~d} v^{\prime} E\left(u^{\prime}, v^{\prime}\right) ;
$$

the correlation function of the process is the cosine transform

$$
\int_{-\infty}^{\infty} \mathrm{d} u \int_{-\infty}^{\infty} \mathrm{d} v E(u, v) \cos (u x+v y+\sigma(u, v) t)
$$

This has recently been used as a model for surface waves in the open ocean ; the author suggests that it may also be applicable to other geophysical phenomena such as microseisms or perturbations of the ionosphere.

The main part of the study is concerned with the use of the limiting representation to derive the following properties : (1) the probability distribution of $\zeta$ and the components of slope $\zeta_{x}$, $\zeta_{y}$ at any point ; (2) the average number of zeros of $\zeta$ per unit distance along a line in an arbitrary direction in the $x-y$ plane; (3) the average length of surface contours per unit area and the distribution of their direction (4) the average densities of maxima, minima and 'specular' points (points where $\zeta_{x}$, $\zeta_{y}$ take given values) per unit area ; (5) the probability distribution of the velocities of zeros of $\zeta$ along a given line; (6) the probability distribution of the velocities of contours and 'specular' points; (7) the probability

* Philosophical Transactions of the Royal Society of London. Series A : Mathematical and Physical Sciences. No. 966, Vol. 249 (21 February 1957): The Statistical Analysis of a Random, Moving Society, 1957.) 21s. 